\title{
Wild weather can send greenhouse gases spiralling
}

Researchers get to grips with effects of heat, drought and storms on carbon release.

\section{BY QUIRIN SCHIERMEIER}

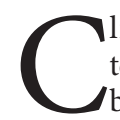

limate change has a disconcerting tendency to amplify itself through feedback effects. Melting sea ice exposes dark water, allowing the ocean to soak up more heat. Arctic warming speeds the release of carbon dioxide from permafrost. And, as researchers discussed at a meeting last week in Seefeld, Austria, climate extremes - heatwaves, droughts and storms - can hamper plant growth, weakening a major buffer against the rise of $\mathrm{CO}_{2}$ in the atmosphere.

"Heatwaves and droughts will very likely become more frequent in a warmer climate, and ecosystems will somehow respond," says Philippe Ciais, a carbon-cycle researcher at the Laboratory of Climate and Environmental Sciences in Gif-sur-Yvette, France. "More storms will add an extra dimension to the problem."

The meeting was organized by the CARBOExtreme project, a $€ 3.3$-million (US\$4.5million) collaboration of 27 groups from 12 countries, funded by the European Union. Attendees showed off an array of tools for uncovering how extreme events affect terrestrial carbon cycles, including numerical models, $\mathrm{CO}_{2}$ flux measurements and field experiments. The challenge now, says Ciais, is to predict how the frequency of climate extremes will change, and to model the intricate physiological responses - some of which are poorly understood - of plants and ecosystems.

Land plants create a huge carbon 'sink' as they suck $\mathrm{CO}_{2}$ out of the air to build leaves, wood and roots. The sink varies from year to year, but on average it soaks up one-quarter of the annual $\mathrm{CO}_{2}$ emissions from the burning of fossil fuels. And events such as droughts, wildfires and storms are likely to "cause a pronounced decline" in the sink, says Markus Reichstein, a carbon-cycle scientist at the Max Planck Institute of Biogeochemistry in Jena, Germany, who coordinates CARBO-Extreme.

Climate anomalies have already had a detectable impact. Satellite observations and data from $\mathrm{CO}_{2}$ measurement towers suggest that extreme events reduce plant productivity by an average of $4 \%$ in southern Europe and $1 \%$ in northern Europe, says Reichstein. That lowers annual carbon uptake by 150 million tonnes - equivalent to more than $15 \%$ of Europe's annual man-made $\mathrm{CO}_{2}$ emissions. The most extreme events can

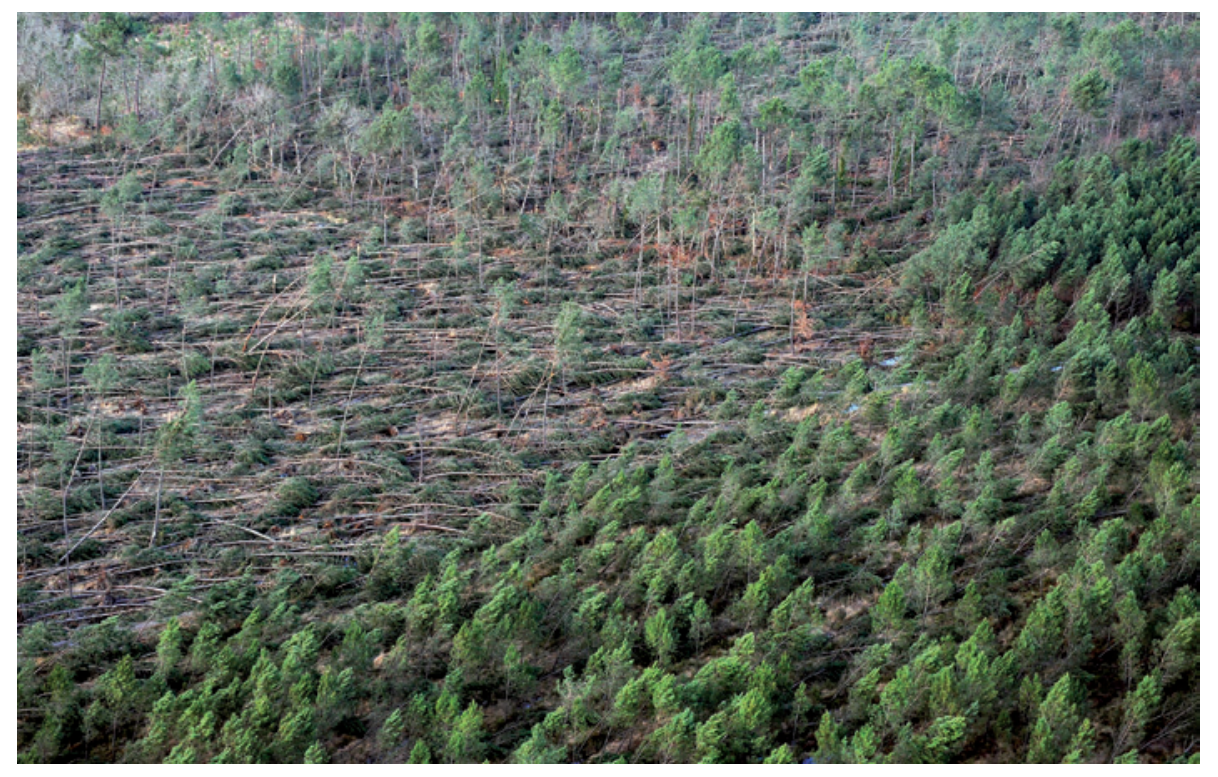

A storm in southern France in 2009 left splintered trees and a weakened carbon sink.

turn forests and grasslands from carbon sinks to sources. In 2003 alone, a record-breaking heatwave in Europe led to the release of more $\mathrm{CO}_{2}$ than is normally locked up over four years ${ }^{1}$.

So far, scientists have detected no increase in extreme weather events. But they expect one. Reindert Haarsma, a climatologist at the Royal Netherlands Meteorological Institute in De Bilt, forecasts a surge in hurricane-strength storms such as 1999's Lothar, which raged northeastward from the Bay of Biscay, slashing forest biomass by 16 million tonnes. By the end of this century, model studies suggest, storms similar to Lothar and another that caused huge damage in France in 2009 will become 25 times more common in Europe ${ }^{2}$. The probability of major heatwaves in Europe is expected to increase up to tenfold by mid-century ${ }^{3}$.

Lack of water makes plants less capable of fending off pathogens and insects. After the 2003 heatwave, caterpillars devastated Mediterranean oak forests near Montpellier in France. Researchers have presumed that this triggered a large carbon release, but such responses are hard to predict. Severe droughts in 2005 and 2010 in the Amazon basin seem to have released much less $\mathrm{CO}_{2}$ than expected, says Ciais."In some ecosystems, small disturbances can have a large impact," he adds. "In others, even significant anomalies seem to cause only little harm."
CARBO-Extreme teams have conducted field experiments that simulated drought in different climates and vegetation types, from Atlantic pine forests to alpine meadows. Unpublished results show that in grasslands, drought markedly slowed photosynthesis, which stores carbon in leaves, roots and soil. It had a smaller effect on soil respiration, which releases carbon, so the net result was a decline in carbon uptake.

The experiments also showed that plants and soils keep a 'memory' of disturbances, says Michael Bahn, an ecologist at the University of Innsbruck in Austria who oversees a grassland experiment. He simulated a series of droughts, and found that later ones had a larger effect on net carbon release. Existing biosphere models do not capture such effects, which Bahn thinks might be due to changes in soil microbes.

Such omissions could lead to a large bias in the models. The world's soils contain almost 100 gigatonnes of carbon - twice as much as the entire atmosphere. Just a $10 \%$ increase in soil-respiration rates, says Bahn, would release more $\mathrm{CO}_{2}$ in a year than humans pump out.

1. Ciais, P. et al. Nature 437, 529-533 (2005).

2. Haarsma, R. J. et al. Geophys. Res. Lett. http:// dx.doi.org/10.1002/grl.50360 (2013).

3. Barriopedro, D., Fischer, E. M., Luterbacher, J., Trigo, R. M. \& García-Herrera, R. Science 332, 220-224 (2011). 